\title{
Do women with pure stress urinary incontinence need urodynamics?
}

Digesu GA, Hendricken C, Fernando R, Khullar V

Department of Urogynaecology, St Mary's Hospital, Imperial College, London, UK

Urology. 2009; 74: 278-81

Objectives: To evaluate the value of performing urodynamic investigations in the assessment of women with a history of pure stress urinary incontinence (SUI).

Methods: Consecutive women with lower urinary tract symptoms were studied retrospectively. Urinary symptoms were determined from the frequency-volume chart and symptom section of the King's Health Questionnaire. Only women with pure SUI symptoms were included.

Results: A total of 3428 women aged 24-81 years were studied. Only 308 women $(8.9 \%)$ could be classified as having pure SUI from the questionnaire. Of these, 241 of women $(78.2 \%)$ had urodynamic stress incontinence, 23 women $(7.5 \%)$ had detrusor overactivity, 9 women $(2.9 \%)$ had mixed urodynamic diagnosis, and 35 women $(11.4 \%)$ had inconclusive urodynamics. Postvoid residual volumes greater than $100 \mathrm{~mL}$ were noted in $24(7.8 \%)$ women.

Conclusions: Our results show that urodynamic investigations provide useful information in the assessment of women with a history of pure SUI, because as many as $20 \%$ of them might not need surgery as the first line of treatment.

\section{Editorial Comment}

The authors review their experience in 3428 women who were evaluated with lower urinary tract symptoms. Patients with a history of daytime frequency, nocturia, urgency and urinary urge incontinence were excluded from this study. The remaining less than $10 \%$ (308 women - 8.9\%) were evaluated urodynamically. It was noted that $78.2 \%$ had urinary stress incontinence, $2.9 \%$ had both urinary stress incontinence and detrusor overactivity while $7.5 \%$ had detrusor overactivity while the remaining 35 patients $(11.4 \%)$ had negative diagnostic urodynamics. Later ambulatory urodynamic studies showed that all these patients had detrusor overactivity. Further evaluation of the study group revealed a poor correlation between severity of the urinary incontinence based on bladder diary and that quantified by urodynamic study.

This paper presents the very contemporary debate on which patients need what studies and how much evaluation is required prior to proceeding with surgery. This topic is not new as evidenced by past papers on same by thought leaders such as McGuire et al three decades ago (1). It is noteworthy to see that the rate of patients with detrusor overactivity from the reviewed paper and that quoted from the paper by McGuire et al is almost identical (1). The debate on the evaluation of the incontinent patient may be expanded to multi-channel fluoroscopic urodynamics studies versus clinical acumen combined with eyeball urodynamics. The facility and economic utility of eyeball urodynamics is such that a review of this technique merits discussion (2).

\section{References}

1. McGuire EJ, Lytton B, Kohorn EI, Pepe V: The value of urodynamic testing in stress urinary incontinence. J Urol. 1980; 124: 256-8.

2. Romanzi LJ, Heritz DM, Blaivas JG: Preliminary assessment of the incontinent woman. Urol Clin North Am. 1995; 22: 513-20.

Dr. Steven P. Petrou

Professor of Urology, Associate Dean Mayo School of Graduate Medical Education

Jacksonville, Florida, USA

E-mail: petrou.steven@mayo.edu 